\title{
Glucose-6-Phosphate Dehydrogenase Measurement
}

National Cancer Institute

\section{Source}

National Cancer Institute. Glucose-6-Phosphate Dehydrogenase Measurement. NCI

Thesaurus. Code C80184.

The determination of the amount of glucose- 6 -phosphate dehydrogenase present in a sample. 